\title{
VHF radar observations of gravity waves at a low latitude
}

\author{
G. Dutta, B. Bapiraju, P. Balasubrahmanyam, H. Aleem Basha \\ Anwarul-uloom College, Osmania University, Hyderabad - 500 001, (A.P.), India \\ Received: 16 February 1998 / Revised: 21 October 1998 / Accepted: 9 December 1998
}

\begin{abstract}
Wind observations made at Gadanki $\left(13.5^{\circ} \mathrm{N}\right)$ by using Indian MST Radar for few days in September, October, December 1995 and January, 1996 have been analyzed to study gravity wave activity in the troposphere and lower stratosphere. Horizontal wind variances have been computed for gravity waves of period (2-6) h from the power spectral density (PSD) spectrum. Exponential curves of the form $e^{Z / H}$ have been fitted by least squares technique to these variance values to obtain height variations of the irregular winds upto the height of about $15 \mathrm{~km}$, where $Z$ is the height in kilometers. The value of $H$, the scale height, as determined from curve fitting is found to be less than the theoretical value of scale height of neutral atmosphere in this region, implying that the waves are gaining energy during their passage in the troposphere. In other words, it indicates that the sources of gravity waves are present in the troposphere. The energy densities of gravity wave fluctuations have been computed. Polynomial fits to the observed values show that wave energy density increases in the troposphere, its source region, and then decreases in the lower stratosphere.
\end{abstract}

Key words. Meteorology and atmospheric dynamics (middle atmosphere dynamics; turbulence; waves and tides)

\section{Introduction}

It is now established that the momentum deposition by internal gravity waves in the middle and upper atmosphere provide significant forcing to the mean flow originally discussed by Hines (1960). There have been numerous studies since then using various techniques to quantify these waves in the mesosphere and thermosphere (Murphy and Vincent, 1993; Manson and Meek, 1993; Vincent, 1994). Recent improvements in MST radar facilities have provided good opportunities to observe the lower, middle and upper atmosphere with better temporal and spatial resolution (Balsley and Gage, 1980; Röttger and Schmidt, 1980; Woodman, 1980a, b).

Frontal systems, convection, wind shear and topography are thought to be significant sources of gravity wave activity. Fritts and Nastrom (1992) have attempted to identify various tropospheric sources of gravity waves. In spite of significant advancements, there have been very few studies of gravity wave activity in the tropical troposphere using radar observations. Chang et al. (1997) used ST radar data from Christmas Island $\left(1.95^{\circ} \mathrm{N}, 157.30^{\circ} \mathrm{W}\right)$ to study tropospheric gravity waves. They found a broad range of frequencies associated with gravity wave activity in the troposphere. They applied two different cleaning algorithms ACR and SEP as explained in their paper and observed that small differences in cleaned data sets can create large differences in gravity wave variance and momentum flux estimates in the lower atmosphere. According to them, stringent criteria of outlier rejection discards more high frequency information affecting gravity wave estimations and makes the choice of algorithm an extremely difficult task.

It is observed that gravity waves do not propagate equally in all directions. The shorter period waves travel obliquely at small zenith angles and dissipate their energy quickly; whereas the longer period waves travel at large zenith angles and penetrate to greater atmospheric heights (Kiffaber et al., 1993). Analyzing wind data from Canadian Prairies MF radar network, Hall et al. (1995) found that the (2-6) hour gravity wave band was spatially uniform and did not get contaminated by locally random noise. This study presents an estimation of gravity wave intensity of periodicity between (2-6) h from radar data in the troposphere and lower stratosphere over a low latitude station, i.e. Gadanki $\left(13.47^{\circ} \mathrm{N}, 79.18^{\circ} \mathrm{E}\right)$.

\section{Experiment and data processing}

The powerful Indian MST radar installed at Gadanki operates at $53 \mathrm{MHz}$ frequency with an average power 

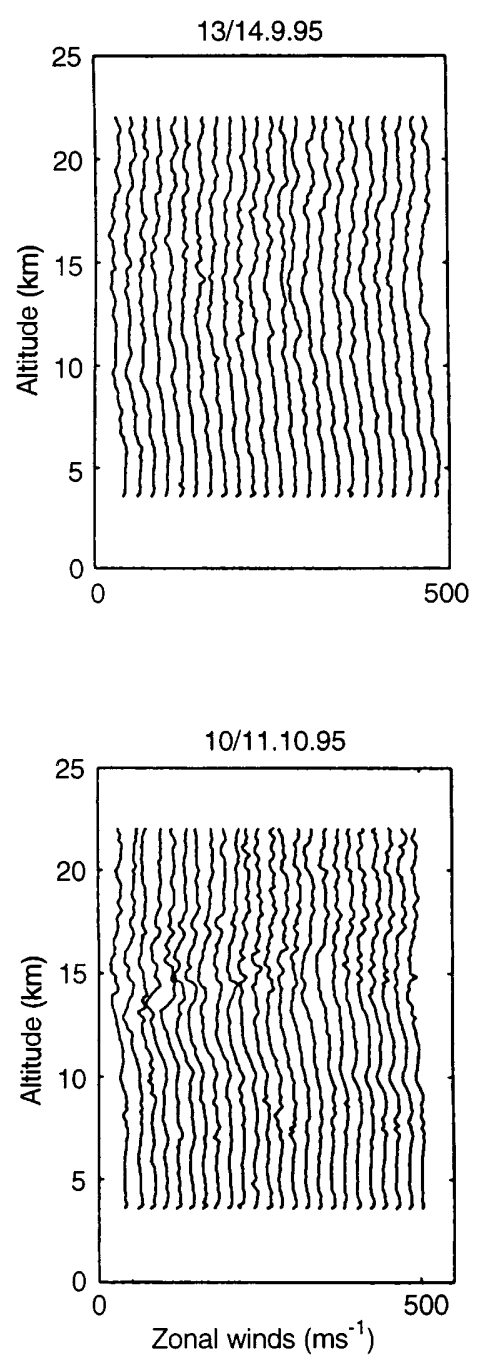
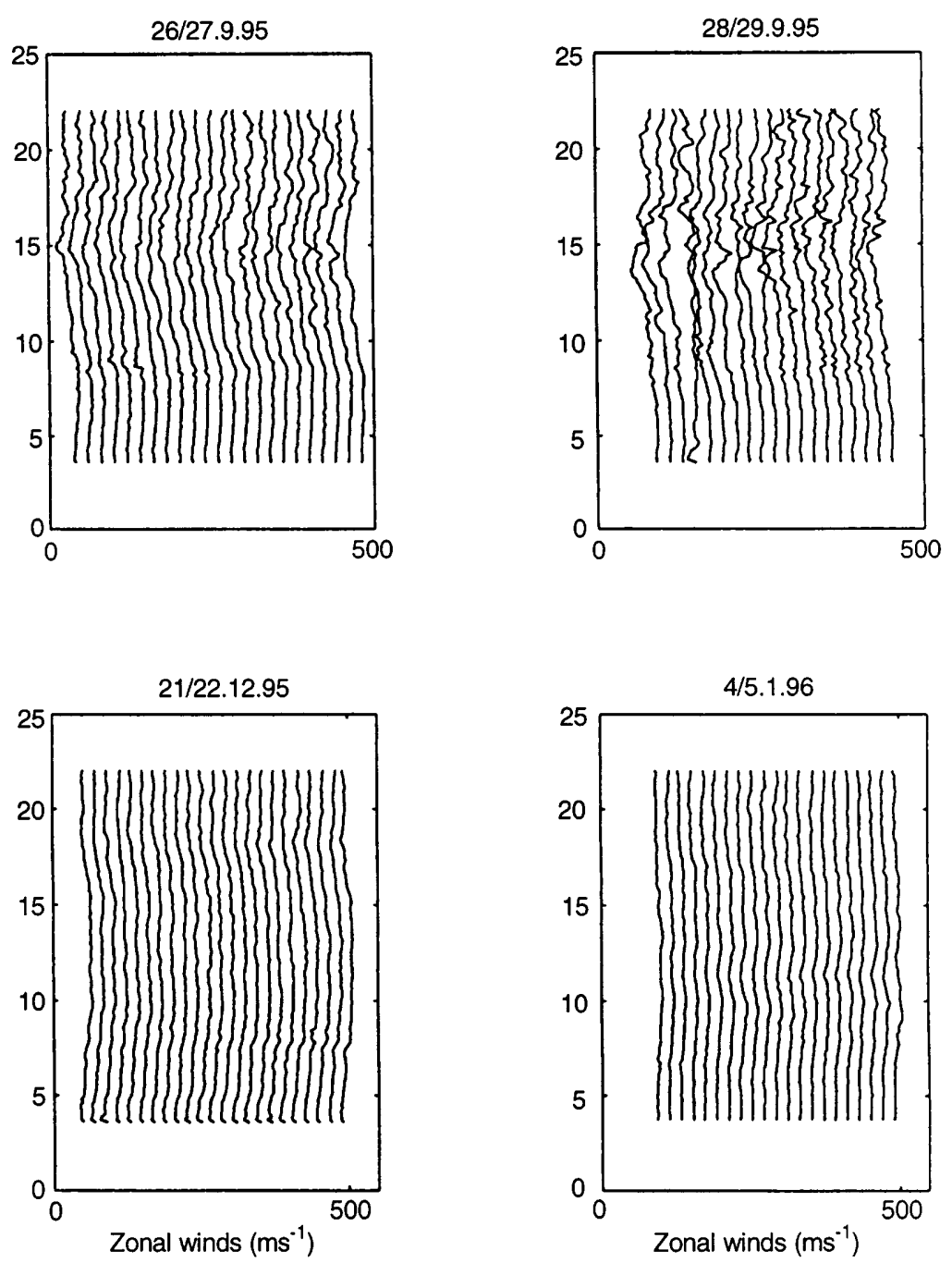

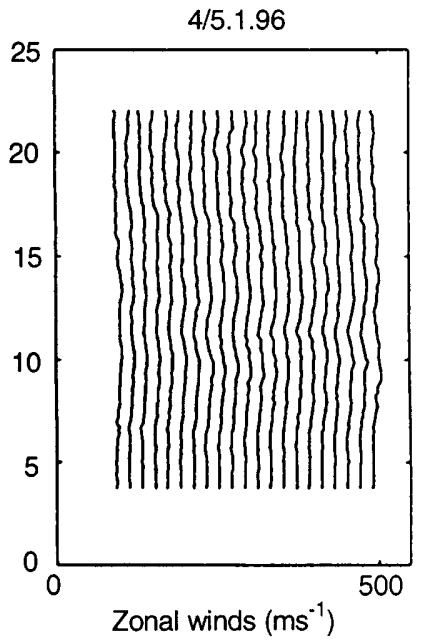

Fig. 1. Profiles of eastward winds on different days corresponding to observational hours. Successive profiles are displaced by $20 \mathrm{~ms}^{-1}$

aperture product of $\sim 7 \times 10^{8} \mathrm{Wm}^{2}$ and provides an excellent opportunity to study mesoscale processes like gravity waves with a height resolution of $150 \mathrm{~m}$ in the troposphere and lower stratosphere. A detailed description of the system has been given by Rao et al. (1995), and Kishore (1993). Data were collected on 13-14 September, 26-27 September, 28-29 September, 10-11 October, 21-22 December, 1995 and 4-5 January, 1996. The diurnal cycle common mode hourly observations started at 10 a.m. (local time) on each specified date and ended at 8 a.m. of the next day except on three days (11 October, 22 December and 5 January) when the radar operated till 9 a.m. Data for 6 p.m. on 13 September and 9 p.m. on 26 September were missing which have been filled up by linear interpolation. Collection of data on 28 September, 1995 and 4 January, 1996 started at 2 p.m. and that on 21 December, 1995 at 11 a.m. The spectral data are collected by the radar using 6-beam positions (east, west, zenith-X, zenith-Y, north, south) with $16 \mu \mathrm{s}$ coded pulse and $1 \mathrm{~ms}$ inter-pulse period.

The complex time series of the decoded and integrated signal samples are subjected to the process of FFT for on-line computation of the Doppler power spectra for each range bin of the selected range window. The Doppler spectra are recorded on a magnetic tape for offline processing. The off-line data processing for parametrization of the Doppler spectrum involves five steps, namely, (1) the removal of dc, (2) estimation of the average noise level, (3) the removal of interference, if any, (4) incoherent integration (further to that done online), and (5) computation of the three low-order (0th, 1 st, and 2nd) moments. The dc contributions from nonfading clutter and uncancelled system biases, if any, are eliminated by notching out the zero frequency and averaging the two adjacent doppler bins to interpolate for a new zero frequency value. For estimating the average noise level an objective method developed by Hilderband and Sekhon (1974) has been adopted here. This technique is based on the statistics of a Gaussian random variable and the expected relationship between mean and variance for the spectrum of a white noise source. The noise level thus determined is subtracted from the received power for each Doppler bin. Any interference band that might run through the entire range window, as experienced often, is subtracted out by estimating it in a range bin where it dominates the real 

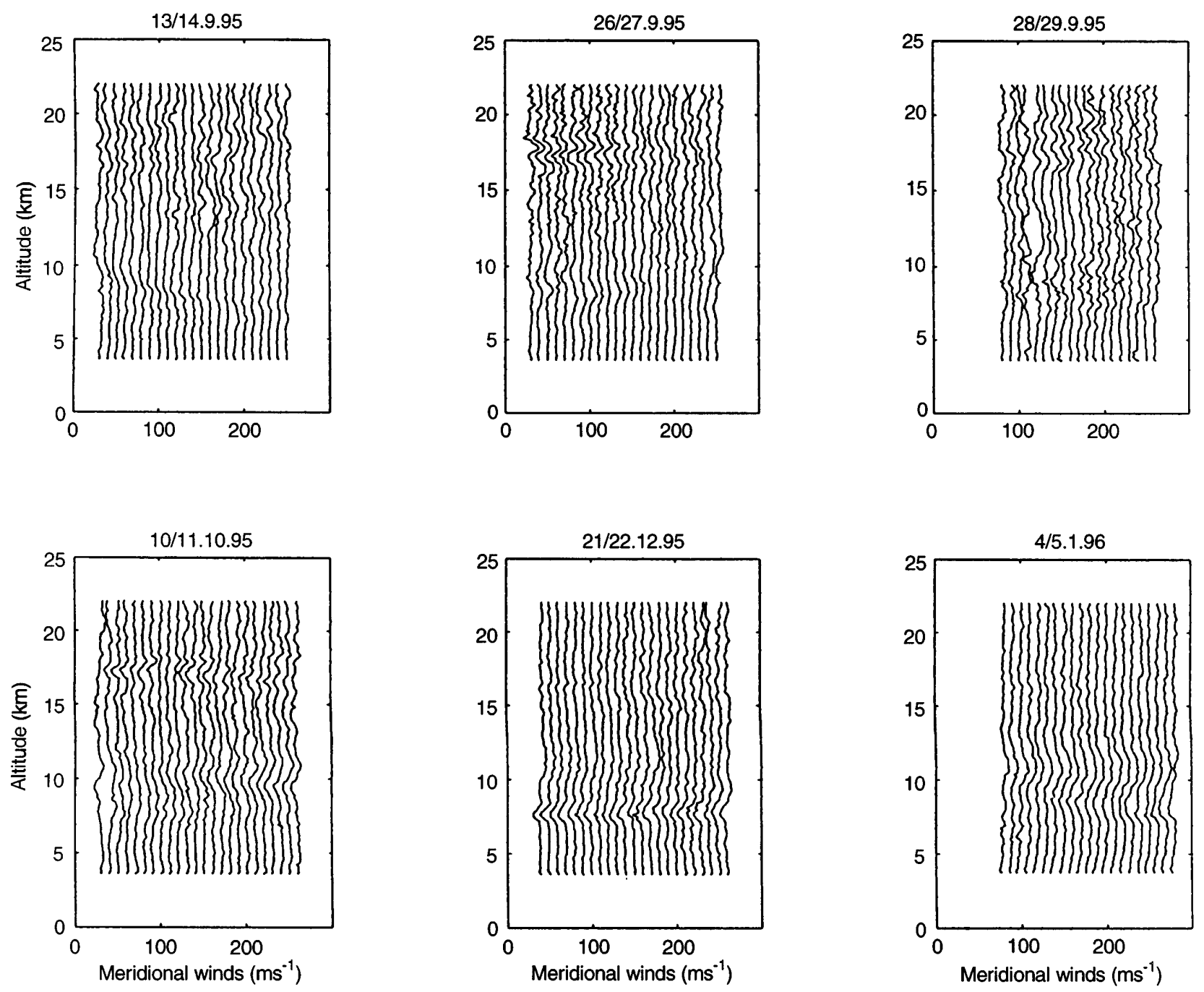

Fig. 2. Same as Fig. 1, but for northward winds. Successive profiles are displaced by $10 \mathrm{~ms}^{-1}$

signal. At this stage any incoherent integration of the spectra, further to that already carried out on-line, is implemented if, so required, to improve the signal detectability, although at the expense of time resolution. The total range is then divided into specified number of windows and for each window the following criteria are set up for adaptive tracking of the signal from range bin to range bin, (a) Doppler window, (b) SNR threshold and (c) maximum wind shear. Then five potential spectral peaks are selected within the specified Doppler window for each range bin and in the first scan, the prominent peak in each range bin is checked against the SNR threshold and accepted if the criterion is satisfied. If the SNR criterion is not met, the most prominent peak which meets the wind shear criterion is taken to represent the signal. The range bins that still remain unrepresented are filled in through interpolation of the spectral moments computed for the closest range bins. The parameters used for the three criteria are so adjusted as to provide the best Doppler profiles as judged by visual inspection.

The three low order spectral moments are computed then through numerical integration using the expression given by Woodman and Guillen (1985). The three moments represent the signal strength, the weighted mean Doppler shift, and half-width parameters of the spectrum. The mean Doppler shift provides a direct measure of the radial velocity of scattering irregularities acting as tracers of the background wind. It is straight forward to derive the three components of the wind vector from measurements taken at a minimum of three non planar beam positions. When observations are made at more than three look angles, as we normally do, the wind vector can be determined in a least square sense (Sato, 1989).

\section{Method of analysis}

The zonal and meridional wind data of each specified day corresponding to different hours are shown in Figs. 1 and 2. Available data of zonal and meridional winds for each day were detrended and high-pass filtered with a cut off period of 6 hours. Figure 3 shows the filtered zonal winds as observed at certain heights on each day. Downward phase progression can be identi- 

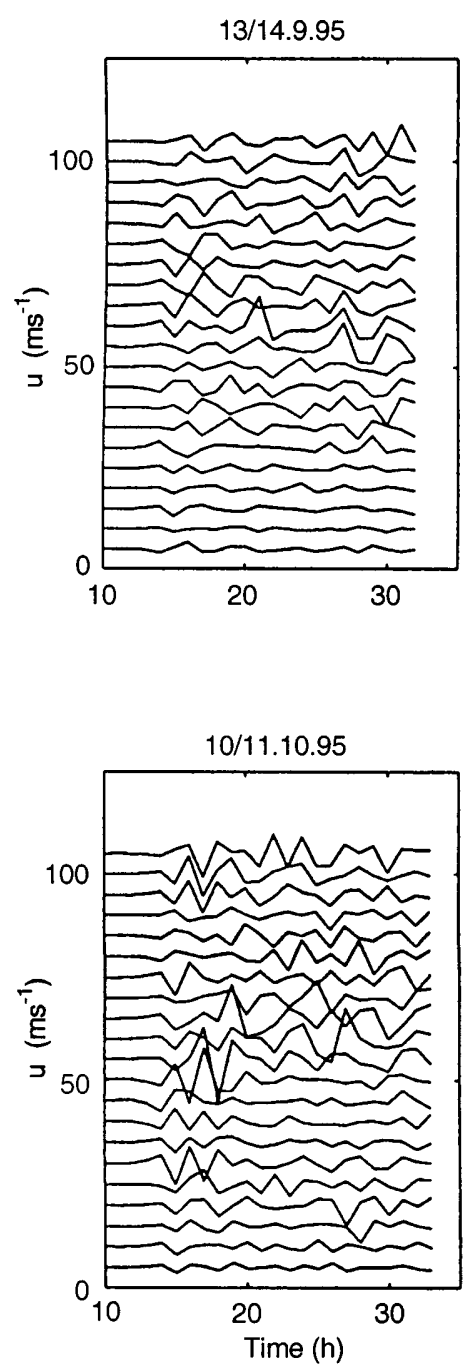
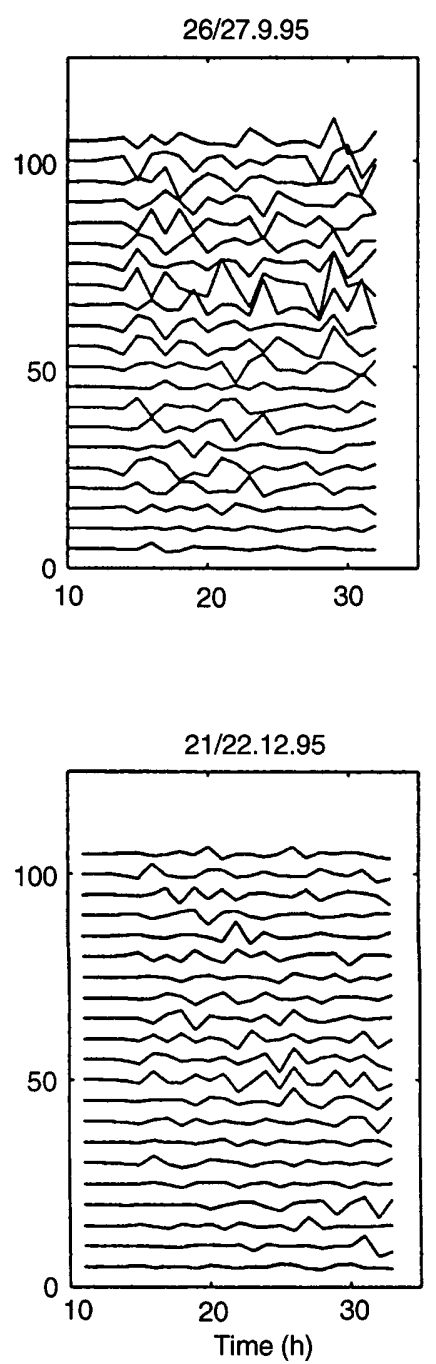
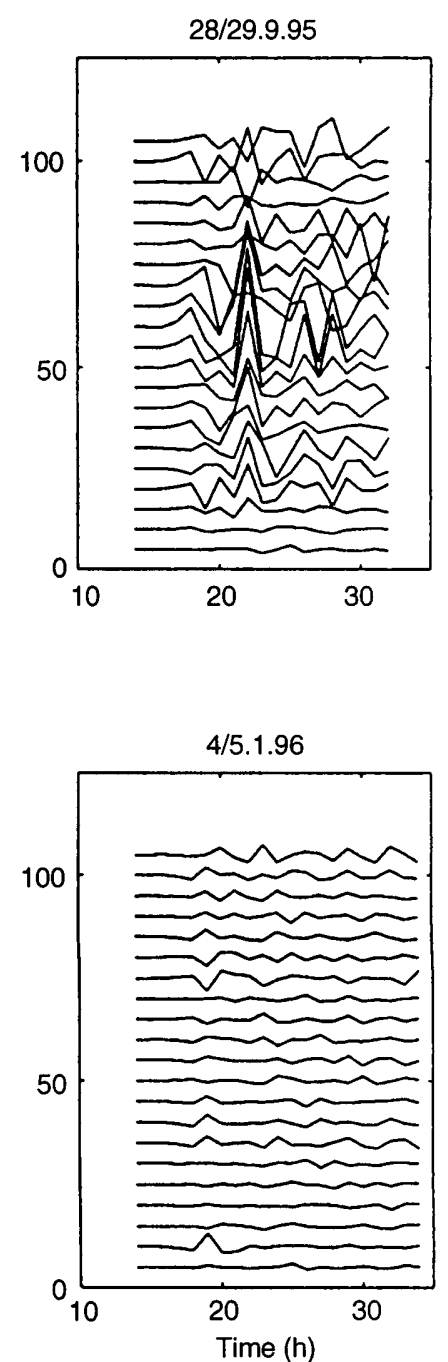

Fig. 3. Temporal variations of zonal winds at 21 heights between 6 and $21 \mathrm{~km}$. Successive plots are displaced by $5 \mathrm{~ms}^{-1}$

fied in the lower stratosphere whereas the waves appear to propagate both upward and downward in the troposphere as also observed by Tsuda et al. (1994a) and Hirota and Niki (1986). Prominent peaks of gravity waves in this band correspond to $(2-4) \mathrm{h}$ as can be identified in the frequency spectra of Fig. 4. To study gravity wave activity, we have subjected the filtered wind data to PSD (power spectral density) analysis. PSD components of zonal and meridional winds at each height have been added up to compute altitude profiles of the mean square amplitude of gravity wave activity $\left(\Delta \mathrm{V}^{2}\right)$. Variance has also been calculated by the normal procedure i.e. $\overline{\mathrm{u}^{\prime 2}+\mathrm{v}^{\prime 2}}$ and is found to agree extremely well with the PSD technique. The gravity wave variances so derived have then been multiplied with the model atmospheric density (CIRA 86) to produce height variations of gravity wave energy in the band of (2-6) h.

\section{Variance studies}

Figure 5 depicts the altitude variations of variance $\left(\Delta \mathrm{V}^{2}\right)$ for different days. Since gravity wave activity appears to increase exponentially with height, we have fitted curves (solid lines) of the form $e^{Z / H}$ by least square technique to the data points where $Z$ is the height in kilometers. The scatter of the data points on all the days in the lower stratosphere clearly shows that they do not follow the same curves as in the troposphere and hence we have restricted curve fittings to an altitude of approximately $15 \mathrm{~km}$, which is below the tropopause. The computed values of $H$ are $3.61 \mathrm{~km}, 3.80 \mathrm{~km}, 2.91 \mathrm{~km}, 5.25 \mathrm{~km}$, $4.77 \mathrm{~km}$, and $7.61 \mathrm{~km}$ respectively for different days of observations. The dotted curves are of the form $e^{Z / H_{0}}$ where $H_{0}$ is the scale height of neutral atmosphere which has been taken as $8 \mathrm{~km}$ for the troposphere. The dotted curves have been normalized to match the solid curves at the lowest heights of observations.

It is expected that as the density of neutral atmosphere falls exponentially upwards, the gravity wave amplitudes will grow accordingly. But the values of $H$ being less than $H_{0}$ suggest that the waves are growing at a faster rate or they are gaining energy while propagating upwards in the troposphere. This clearly shows that major sources of gravity waves are located in the troposphere. Using radiosonde measurements, 

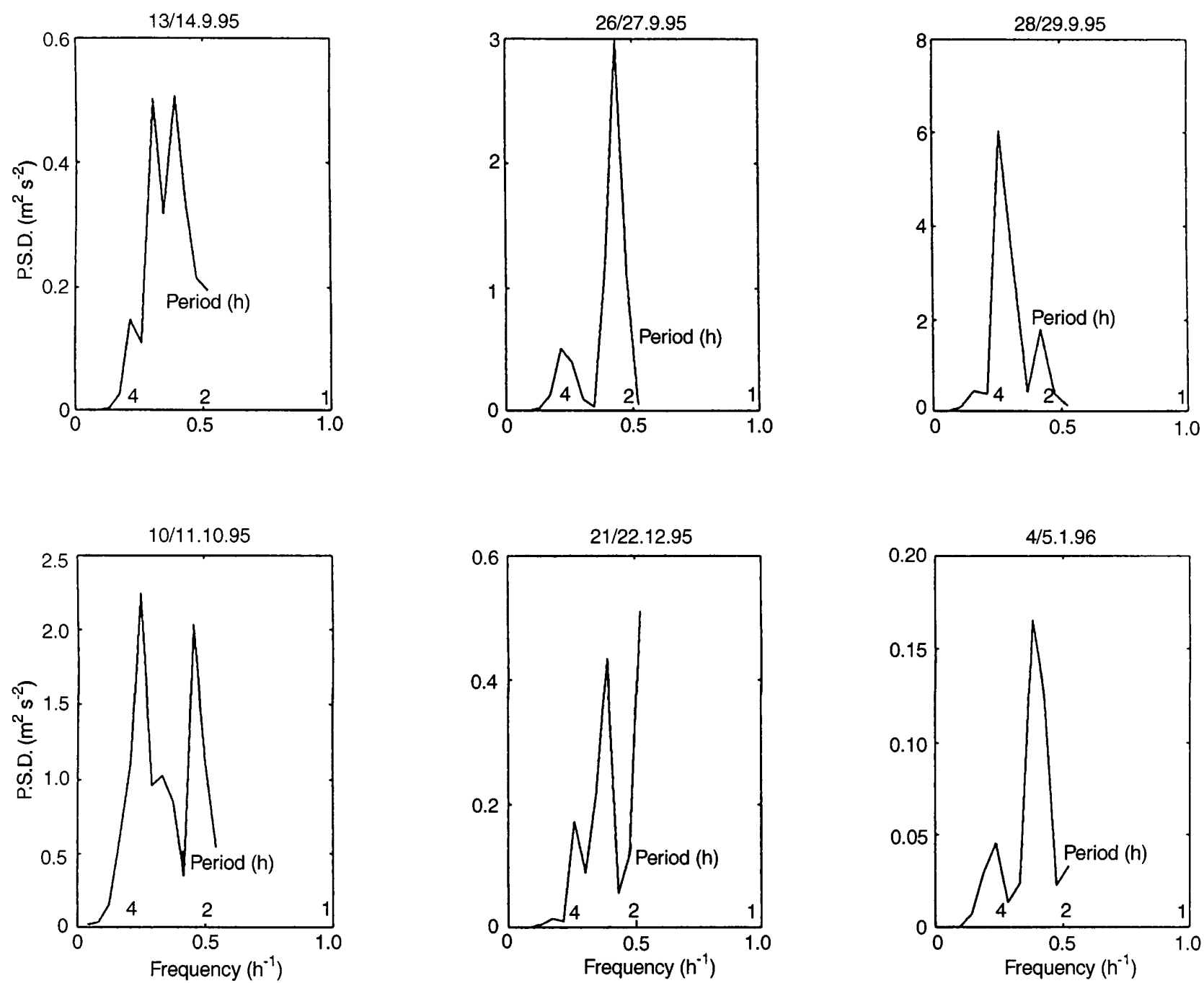

Fig. 4. Frequency spectra of zonal winds at $15 \mathrm{~km}$ on different days

Tsuda et al. (1994a) showed that gravity waves were mostly generated in the middle troposphere and that the waves which reached the stratosphere were propagating upwards. Most of the work done on gravity waves in the mesosphere suggest that their sources are in the troposphere. Vincent (1984) and Eckermann and Vincent (1989) supported this idea from their studies of rotary spectra and showed that more than $65 \%$ of the wave energy is due to upward propagating waves. Hocking (1996) while reviewing coupling processes between middle atmosphere and lower ionosphere concludes that a high percentage of gravity wave sources are in the troposphere and this, in itself, is an important result.

The average variance as observed in the present study ranges between 0.2 and $22 \mathrm{~m}^{2} \mathrm{~s}^{-2}$. Tsuda et al. (1994a) estimated a wind velocity variance between 1 and $20 \mathrm{~m}^{2} \mathrm{~s}^{-2}$ over East Java, Indonesia. The average estimate of variance given by Chang et al. (1997) for Christmas Island ranges between 1 and $5 \mathrm{~m}^{2} \mathrm{~s}^{-2}$. Their ACR daily variances ranged between 0.00015 and $11.20 \mathrm{~m}^{2} \mathrm{~s}^{-2}$ and the SEP variance between 0.0022 and $3.65 \mathrm{~m}^{2} \mathrm{~s}^{-2}$. Our values are quite reasonable when compared with ACR variances except for one day i.e.
(28-29) September, 1995. The difference between the two stations could be attributed to the complicated topography of Gadanki which is surrounded by small hills with heights between 300 to $800 \mathrm{~m}$, whereas Christmas Island is a low atoll near the middle of the Pacific Ocean. Tsuda et al. (1994b) have shown that long period gravity waves with periods of (2-21) h are mainly generated near the ground, probably due to the interaction of the surface winds with topography, while short-period components $(5 \mathrm{~min}-2 \mathrm{~h})$ seem to be excited near the peak of the jet stream. The variance values as calculated by us do not change appreciably up to an altitude of $10 \mathrm{~km}$ and rise sharply thereafter, attaining high values below the tropopause. Tsuda et al. (1994a) studied the variance of small-scale temperature fluctuations and detected large values of variance near the tropopause throughout the observation period which decreased at $18-21 \mathrm{~km}$ altitude and again became enhanced in the overlying region. They also found good correlation between gravity wave variance and relative humidity suggesting gravity wave generation to be closely related to cloud convection in the equatorial region. There was no apparent convection on the 

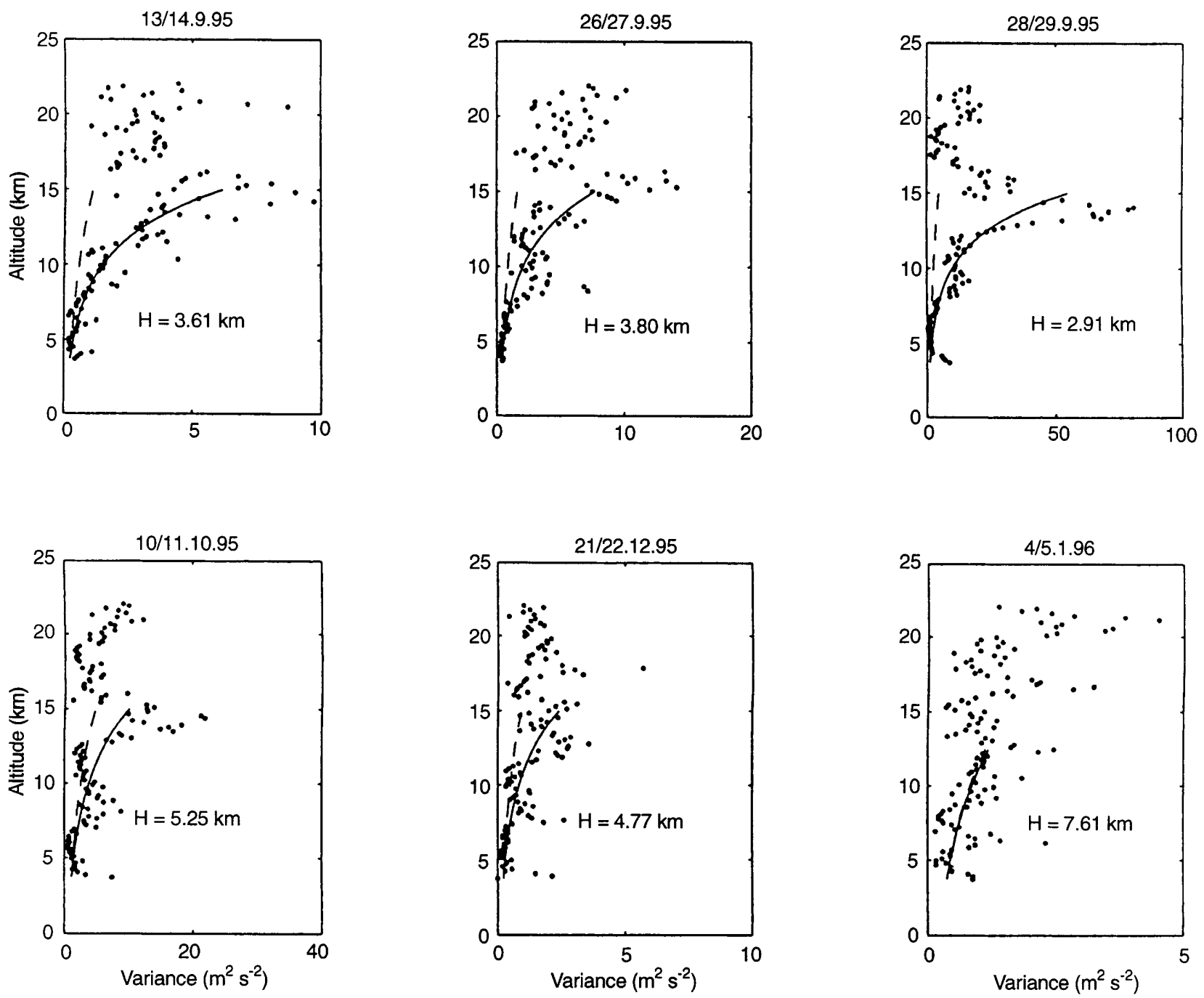

Fig. 5. Altitude variations of the mean square wind fluctuations (points). The solid lines represent exponential curves fitted by least squares method to the observations. The dashed curves are exponential curves with scale height equal to the neutral density scale height (8 km)

particular experimental days in the present study, but the average level of convection (humidity) in the tropics and convective activity in neighbouring equatorial stations, if any, could provide the gravity wave forcing.

\section{Variation of gravity wave energy with height}

Figure 6 shows the variations of energy densities $\rho_{0} \Delta \mathrm{V}^{2}$ with height for all six days. Polynomials of high order have been fitted to the data points. It is apparent from the diagrams that the energy density of gravity waves increase in the troposphere and decrease in the lower stratosphere. Allen and Vincent (1995) used highresolution radiosonde measurements and showed that the energy density of gravity waves was larger in the troposphere than the lower stratosphere. Tsuda et al. (1994b) made a detailed study of variation of gravity wave energy. They found that energy of short-period gravity waves between ( 5 min and $2 \mathrm{~h}$ ) was high near the jet stream whereas long, (2-21) h, period gravity waves showed higher energy nearer to the ground. Since we have chosen gravity waves of period (2-6) h, a direct comparison is not possible, but our results agree very well with the short period wave energy structure.

\section{Concluding remarks}

There have been very few studies of gravity wave activity in the troposphere for tropical stations. We have estimated gravity wave variances of periodicity between (2-6) $\mathrm{h}$ in the lower atmosphere by using MST radar data over Gadanki, India. We computed variances by applying PSD technique to the data and the estimates are found to range between 0.2 and $22 \mathrm{~m}^{2} \mathrm{~s}^{-2}$. Gravity wave intensity is found to increase rapidly after about $10 \mathrm{~km}$ reaching high values below the tropopause. Energy densities of these waves show larger values in the troposphere, their source region, compared to those in the lower stratosphere.

Our data analysis is quite rigorous and has yielded results which seem reasonable and agree with those of previous studies. However, long enough data series 

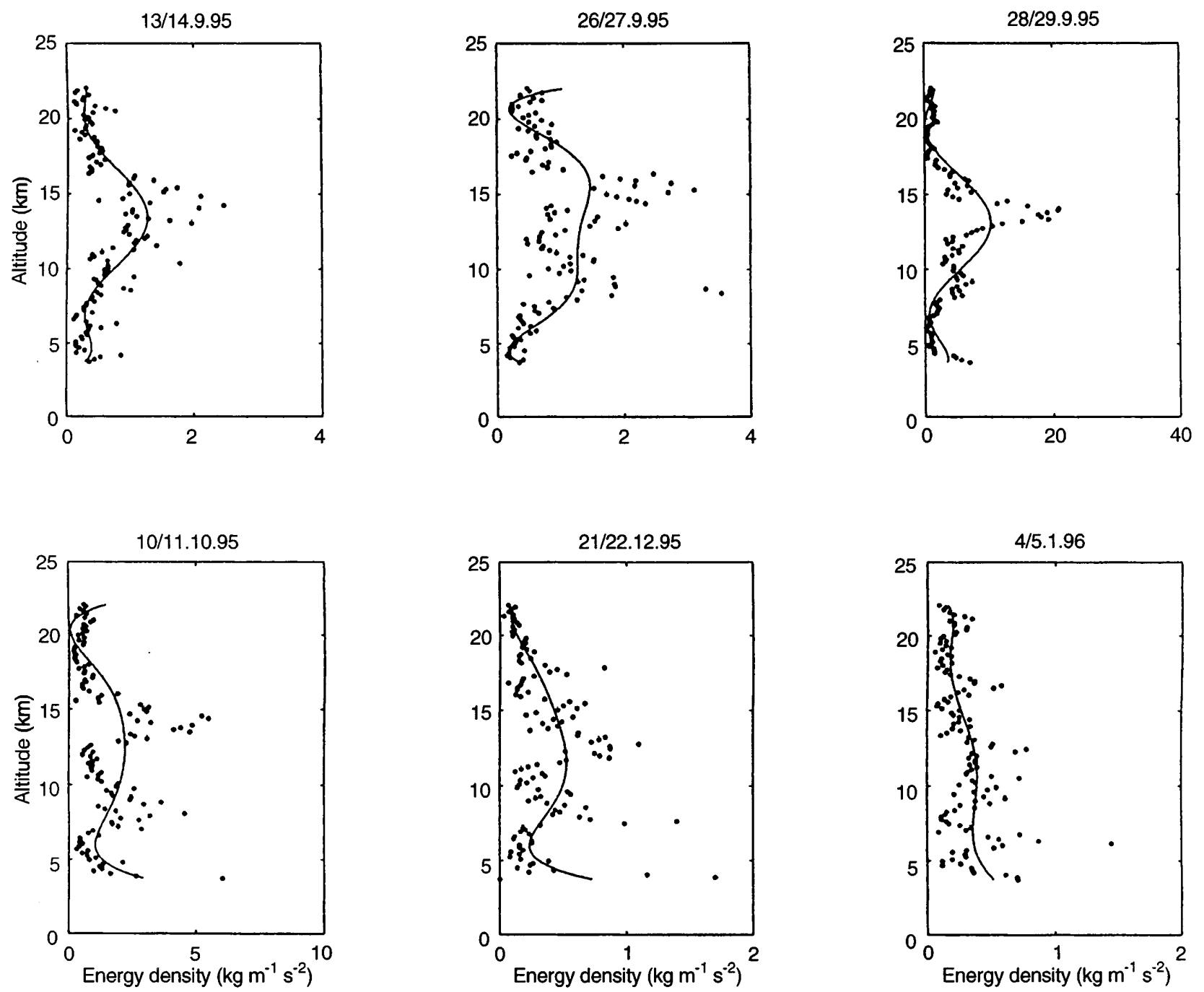

Fig. 6. Height variations of energy densities $\left(\rho_{0} \Delta V^{2}\right)$ of gravity waves

should be analyzed to quantify these waves in the lower atmosphere.

Acknowledgements. The Indian MST Radar Project was funded jointly by DOE, DOS, DOEn, DST, DRDO and CSIR with DOS as the nodal agency. The authors are grateful to Department of Science and Technology, Government of India, for providing financial assistance to run the project. The authors also wish to thank UGC-SVU Centre for MST radar Applications, S. V. University for providing necessary facilities to carry out the research work. Thanks are also due to the anonymous referees for their valuable comments which substantially improved the quality of the work.

Topical Editor F. Vial thanks C. Hall and another referee for their help in evaluating this paper.

\section{References}

Allen, S. J., and R. A. Vincent, Gravity wave activity in the lower atmosphere: seasonal and latitudinal variations, J. Geophys. Res., 100, 1327-1350, 1995.

Balsley, B. B., and K. S. Gage, The MST radar technique: potential for middle atmosphere studies, Pure Appl. Geophys., 118, 452493,1980
Chang, J. L., S. K. Avery, A. C. Riddle, S. E. Palo and K. S. Gage, First results of tropospheric gravity wave momentum flux measurements over Christmas Island, Radio Sci., 32, 727-748, 1997.

Eckermann, S. D., and R. A. Vincent, Falling sphere observations of anisotropic gravity wave motion in the upper stratosphere over Australia, Pure Appl. Geophys., 130, 509532, 1989

Fritts, D. C., and G. D. Nastrom, Sources of mesoscale variability of gravity waves II: frontal, convective and jet stream excitation, J. Atmos. Sci., 49, 111-127, 1992.

Hall, G. E., S. P. Namboothiri, A. H. Manson, and C. E. Meek, Daily, tidal, planetary wave and gravity wave components over the Canadian Prairies, J. Atmos. Terr. Phys., 57, 1553-1567, 1995.

Hilderband, P. H., and R. S. Sekhon, Objective determinations of the noise level in Doppler spectra, J. Appl. Meteorol., 13, 808$811,1974$.

Hines, C. O., Internal atmospheric gravity waves at ionospheric heights, Can. J. Phys., 38, 1441-1481, 1960.

Hirota, I., and T. Niki, Inertia-gravity waves in the troposphere and stratosphere observed by the MU radar, J. Meteorol. Soc. Jpn., 64, 995-999, 1986.

Hocking, W. K., Dynamical coupling processes between the middle atmosphere and lower ionosphere, J. Atmos. Terr. Phys., 58, 735-752, 1996. 
Kiffaber, L. M., D. R. Friesen, D. L. Knutson, and A. W. Peterson, Short gravity wave periodicities during AIDA, J. Atmos. Terr. Phys., 55, 341-354, 1993.

Kishore, P., Atmospheric studies using Indian MST radar - winds and turbulence parameters, $\mathrm{Ph} \mathrm{D}$ Thesis, Sri Venkateswara University Tirupati, India, 1993.

Manson, A. H., and C. E. Meek, Characteristics of gravity waves $(10$ mins- $6 \mathrm{~h})$ at Sanskatoon $\left(52^{\circ} \mathrm{N}, 107^{\circ} \mathrm{W}\right)$. Observations by the phase coherent medium frequency radar, J. Geophys. Res., 98, 20357-20367, 1993.

Murphy, D. J., and R. A. Vincent, Estimates of momentum flux in the mesosphere and lower thermosphere over Adelaide, Australia from march 1985 to February 1986, J. Geophys. Res., 98, 18 617-18 638, 1993.

Rao, P. B., A. R. Jain, P. Kishore, P. Balamuralidhar, S. H. Damle, and G. Viswanathan, Indian MST radar, 1, system description and sample vector wind measurements in ST mode, Radio Sci., 30, 1125-1138, 1995.

Röttger, J., and G. Schmidt, High resolution VHF radar sounding of the troposphere and stratosphere, IEEE Trans. Geo Sci., Electron., G.E., 17, 182-189, 1980.

Sato, T., Radar principles, in Hand book for MAP, Ed. S. Fukao, 30, pp 19-53, SCO STEP Seer, Urbana, III., 1989.
Tsuda, T., Y. Murayama, H. Wiryosumarto, S. B. Harijono, and S. Kato, Radiosonde observations of equatorial atmosphere dynamics over Indonesia, 2, characteristics of gravity waves, J. Geophys. Res., 99, 10 507-10 516, 1994a.

Tsuda T, Y. Murayama, T. Nakamura, R. A. Vincent, A. H. Manson, C. E. Meek, and R. L. Wilson, Variations of the gravity wave characteristics with height season and latitude revealed by comparative observations, J. Atmos. Terr. Phys. 56, 555-568, 1994b.

Vincent, R. A., MF/HF radar measurements of the dynamics of the mesosphere region - a review, J. Atmos. Terr. Phys., 46, 961974, 1984.

Vincent, R. A. Gravity-wave motions in the mesosphere and lower thermosphere observed at Mawson, Antarctica, J. Atmos. Terr. Phys., 56, 593-602, 1994.

Woodman, R. F., High altitude-resolution stratospheric measurements with the Arecibo $430 \mathrm{MHz}$ radar, Radar Sci., 15, 417422, 1980a.

Woodman, R. F., High altitude - resolution stratospheric measurements with the Arecibo $2380 \mathrm{MHz}$ radar, Radar Sci., 15, 423430, 1980 b.

Woodman, R. F., and A. Guillen, Radar observations of winds and turbulence in the stratosphere and mesosphere, J.Atmos.Sci., 31, 493-505, 1985. 